\title{
General Discussion to Papers of Dr Steinberg and Mr Burr
}

Dr MinaIRE (France). I would like to point out the fact that these hypercalcaemia in the mobilisation do not occur only in spinal cord injury patients especially in tetraplegics, but on all types of immobilisation, and if the theory of the low cortisone in the blood is retained then it is difficult to explain the difference. I mean we should find the difference between spinal cord injury and other types because as far as I know there is a different metabolic condition or endocardiological condition in tetraplegics. There is no answer to this main question. We have performed longitudinal studies for I year in about 65 patients, and we have never found a trace of hypercalcaemia above 25 years of age. It is only in your male patients, so it is difficult to discuss the fact between male and female. But the age seems to me very important and now a question to the speaker is 'Did you try to put a patient into a standing position or was it not possible?'

Dr STEINBERG. We did put the patient in a standing position, at least we attempted to but he at the time, because of hypotension when standing, was really not very effective. It was tried many times. I think I would like to indicate again that I am not trying to promote a theory, I think one case does not really permit one to make a hypothesis or a theory but this was a positive observation that has not previously been made. I do not know any more than anybody else why male adolescents are so much more vulnerable than the female adolescents but this is for the literature.

Dr Kewalramani (U.S.A.). I think I can add another case to Dr Steinberg's observation, who was a I5-year-old tetraplegic who had serum calcium levels around I5 per cent. In fact he was investigated and we did cortisone loading tests which had been recommended in patients as an investigational technique. At that time the discussion was shall we treat the patient on calcitonin or shall we treat the patient with steroids? We were able to bring the serum calcium levels down to 10.5 per cent. I definitely do agree with you that the reports of incidents in the literature is much smaller and Fred Minard published four cases in the 'Archives of Physical Medicine' which we have in 1977 and now the paper is ready for presentation. But I would certainly investigate those patients with hypercalcaemia by administering calcitonin with cortisone.

DR G. SMITH (U.S.A.). I greatly enjoyed Dr Steinberg's publication and the work I found fascinating. I can add another patient from my time at Ranchos Los Amigos Hospital. A I5-year-old boy with a T9 complete injury who had been immobilised in bed for 5 months having had five operations all of which were necessary except the first. He was brought to us at the end of this time and it was whilst with us that he began to vomit. This was our first symptom and I wonder whether we could get some indication from you Sir, and from any others as to the initial symptom. The medical people who looked after him were predominantly interested in cardiology and they discovered that with a very high calcium his cardiograph showed some quite terrifying changes. I wonder whether others have experienced this. The result was the poor lad was incarcerated in intensive care in case he should arrest for nearly a month. In fact he never came to any harm at all, he was only treated by electrolyte solutions and the calcium eventually came down. I would be interested to see if other people have had experience of cardiological problems.

DR STEINBER G. In our case the symptoms were not very specific. This was a weak, depressed little boy, very scared, complaining of nausea and probably would not have been a diagnosis of hypercalcaemia had it not been for the examination of calcium which is useless as a test in most cases but in this situation was very helpful. The electrocardiographs were normal.

DR MAURY (France). I would like to indicate the causes of hypercalcaemia in the young patient immobilised with one more of my patients. The urine calcium was increased and the filter renal was normal, calcaemia normal. We have given physiotherapy and the calcuria diminished but the calcaemia increased. 
Dr Kewalramani. We had just the same type of case in our hospital lately. A I 5-year-old boy with a $\mathrm{C}_{5}$ complete lesion had hypercalcaemia. We could not give him steroids because of a gastric ulcer, but his hypercalcaemia disappeared when he was elevated and mobilised.

Dr Chantraine. Just one answer to a question. In the case we had there was the increase of the ST segment on the electrocardiogram were the only EKG changes on this patient. I think in this case too we had a decrease of the bone mass of 50 per cent we measured with the iliac crest biopsy between the first month and the sixth month in this case. It was an I8-year-old boy, and I think that is the main problem, that in older patients the decrease of the bone mass is much lower, maybe just Io or 20 per cent, but in young people, young boys just finishing their growing, the bone mass decrease can be 50 per cent and it would be probably an excess of calcium and that would be part of the causes of the hypercalcaemia.

Prof. Tricot (Chairman). Are there any questions for Mr Burr of the National Spinal Injuries Centre?

DR MeINECKe (Germany). From the series you gave the question arises whether you feel that acidifying the urine is still of any value to prevent stone formation or whether you have come to the conclusion that in spite of that procedure such a high number of stone formations may often be developed.

MR BURR (G.B.). I express a personal opinion which may not represent the feelings of my medical colleagues at Stoke Mandeville, that is that the acidifying therapy is of value if it can be demonstrated that it acidifies the urine, but if in the presence of acidifying therapy the urine remains alkaline due to the activity of the organisms present, then it might in fact be expected to make the situation worse because of the possibility that the acidifying therapy increases the excretion of calcium, magnesium and phosphates. 